Research Article

\title{
Experimental and Numerical Investigations on the Ignition of RBCC Gas-Oxygen/Kerosene Rocket Ejector
}

\author{
Bingyang Liu $\left(\mathbb{D}\right.$, Ping Jin $\mathbb{( D}^{\text {, }}$, Yixin Ma, Yaqun Qi, Guobiao Cai, and Yuanjun Zhang \\ School of Astronautics, Beihang University, Beijing 100191, China \\ Correspondence should be addressed to Yuanjun Zhang; zhangyuanjun@buaa.edu.cn
}

Received 13 July 2021; Accepted 27 October 2021; Published 9 November 2021

Academic Editor: Angelo Cervone

Copyright ( 2021 Bingyang Liu et al. This is an open access article distributed under the Creative Commons Attribution License, which permits unrestricted use, distribution, and reproduction in any medium, provided the original work is properly cited.

\begin{abstract}
The rocket ejector refers to a core component of a rocket-based combined cycle (RBCC) engine. The ignition is of critical significance for rocket ejection. Reliable and stable ignition crucially determines the normal operation of the engine. In this paper, a thrust chamber with coaxial swirl injector for the RBCC rocket ejection was developed and tested. Gas oxygen (GOX) and kerosene acted as propellants. As revealed from the test results, the process of ignition pressurizing comprised four phases. The oxygen prefilling time before ignition slightly impacted the ignition time, whereas it affected the peak pressure of ignition. In a confined range, the peak pressure decreased as the prefilling time was extended. The ignition was simulated by building a numerical model, and the results well complied with the experimentally achieved results. The numerical model is capable of specifically indicating the position of the kernel of fire and the process of flame propagation. The simulation results reveal that the propellant could form a combustible condition within $4 \mathrm{~ms}$. The kernel was $6 \mathrm{~mm}$ away from the injector, located at the oxygen and kerosene mixing interface and approaching the upper wall. The above results reflected the vital role of the central recirculation zone formed by the prefilled oxygen. The ignition energy was transported near the injector under the convection effect, which ignited the stoichiometric mixture, and the entire ignition could reach a stable state within $20 \mathrm{~ms}$. The numerical model which was developed in this paper can help clarify the combustion mechanism.
\end{abstract}

\section{Introduction}

Along with low-cost reusable space transportation systems and hypersonic weapon technology continuous development, the rocket-based combined cycle (RBCC) engine is gradually recognized. The RBCC engine has a high specific impulse and a large thrust-to-weight ratio, which can meet the acceleration and cruise requirements of hypersonic aircraft [1-3]. Because of its excellent performance in the full range of ballistic trajectory, the RBCC engine has become one of the most promising propulsion systems of single-stage to orbit space plane, as well as the next-generation hypersonic aviation aircraft $[4,5]$. In recent years, many studies have been carried out to explore the operation law of the RBCC engine. An et al. [6] investigated the effect of expansion fan on cavity flameholding in a rocket-based combined cycle combustor fueled by ethylene. Successful ignition and flame stabilization were achieved in the combustors with $d / H=1.5,2.0,4.5$, and 7.5. $\mathrm{d} / \mathrm{H}$ was the dimensionless distance between the backward-facing step and the cavity. The result indicates that the expansion fan also significantly decreased the static pressure in the cavity. Li et al. [7] investigated the two-stage fuel injection performance of RBCC under scramjet mode using Reynolds-averaged Navier-Stokes-based CFD modeling. The result revealed that the appropriate axial fuel injection position of the first stage could significantly improve the engine performance under Mach 6. Shi et al. [8] performed an experimental study on ejector-to-ramjet mode transition in a divergent kerosene-fueled RBCC combustor with low total temperature inflow. According to the results, the embedded rocket in the RBCC combustor was critical to the ejector-to-ramjet mode transition, and the ignition and flameholding functions of the hot rocket plume should be fully exploited in the combustion organization.

Compared with liquid oxygen (LOX), the GOX does not require any upstream pressure or pump equipment, nor a 
low-temperature supply system, significantly simplifying the system. Therefore, the rocket ejector developed in this paper chooses GOX/kerosene as the propellants. Numerous studies on the ignition of GOX/kerosene have been conducted. Ignition and flame propagation are dependent of various physical properties in the combustion chamber (e.g., the mixing ratio of the propellant, the initial pressure and temperature in the thrust chamber and their heat transfer characteristics, the total energy deposited by the ignition system, the spark position, convection velocity, average droplet size, and its distribution) [9]. Takegoshi et al. [10-12] of the Kakuda Space Center in Japan performed the tests on the combined cycle engine rocket ejector ignition under different conditions. Kim et al. [13] observed the ignition transition of GOX/kerosene spray by directly visualizing the combustion flow field. It has been found that the early ignition moment will trigger smooth ignition and long ignition delay. They also studied the effect of prefilled oxygen content on the ignition. As the oxygen prefilling time increased, the ignition delay time decreased and the peak value of global $\mathrm{OH} *$ intensity increased exponentially. With the preoxygen injection time reaching over $14 \mathrm{~ms}$, the ignition varied from smooth ignition to two-step ignition [14]. Sheng et al. [15] investigated the ignition issue due to the low reactivity of hydrocarbon fuel when flying at low flight Mach numbers. They found that the low-temperature ignition reduced from 620 to $160^{\circ} \mathrm{C}$ by only adding $3 \%$ borane-dimethyl sulfide (BDMS) and provided an effective method to solve the scramjet ignition problem at low flight Mach numbers.

For gas and liquid mixing combustion, injection forms primarily comprise the shear coaxial injector and the coaxial swirl injector. In this paper, the GOX/kerosene coaxial swirl injection form was adopted. On the whole, the injection method is capable of achieving better atomization quality and high mixing efficiency. The liquid and gas discharge coefficients of this injector were elevated with the increase in the flow rate pressure drop. With the increase in the momentum flow ratio, the spray angle turned out to be narrower. The combustion efficiency reduced with the increase in the mixing ratio and the momentum ratio [16]. Chu et al. [17] investigated the effects of gas-liquid ratio (GLR) on the spray and atomization process of a liquid-centered swirl coaxial injector using the coupled level-set and volume of fluid (CLSVOF) method. The results show that the atomization process becomes dominated successively by the instability of the liquid film, strong gas-liquid interaction, and spray self-pulsation with the increase of GLR. Soller et al. [18] employed GOX/kerosene coaxial swirl injector in oxidizer-rich staged combustion cycle engines. Four design alterations were discussed for their effect on combustion stability. As revealed from the results, combustion stability could be regained by tapering of the recess, whereas with the increase in the fuel injection velocity, satisfactory stability was not achieved. The ignition of kerosene spray was investigated in an aeroengine combustor. Lin et al. [19] investigated the spark ignition of swirling kerosene spray flames using a well-defined simplified combustor. The results indicated that successful ignition sparks were associated with flame kernels that move upstream towards the spray nozzle. Nevertheless, the GOX/kerosene swirl injection thrust chamber has been rarely applied in the rocket ejector of RBCC.

The performance of the engine in ejection mode critically impacts the efficiency of the entire RBCC propulsion system. The ignition of the rocket ejector can determine whether the starting process can proceed smoothly, which should be investigated in depth. Though some basic researches have been conducted on the ignition and combustion characteristics exhibited by GOX/kerosene, these explorations basically remain at the level of small-scale experiments or pure theoretical simulations. In this paper, the ignition of the RBCC rocket ejector with coaxial swirl injection was analyzed. The general pressurizing law of ignition was explored with the test method. Moreover, the effect of oxygen prefilling time on ignition delay and pressure peak was determined by altering the time interval between the oxidant and fuel entering the thrust chamber. Furthermore, to elucidate the mechanism of ignition, a numerical simulation model was built. Given the numerical results, the location of the core, the flame propagation law, and time scale were revealed. The conclusion here is of high significance for predicting and guiding the ignition of the rocket ejector with coaxial swirl injector.

\section{Experimental Setup}

2.1. Combustion Chamber and Injector. Figure 1 illustrates the structure of the burner used here, and the size parameters of the thrust chamber are listed in Table 1. GOX entered the injector via the oxygen inlet pipeline and subsequently entered the thrust chamber via the central hole of the injector. In addition, kerosene entered the injector via the kerosene pipeline and then formed a tangential velocity swirling flow into the thrust chamber through the outer annular gap of the injector. Figure 2 presents the structure diagram of the injector.

\subsection{Hydraulic Characteristics of the Propellant Feed System.} Figure 3 illustrates the propellant supplying system. GOX and kerosene were, respectively, supplied through the upstream tank and then sent into the thrust chamber via pipelines and valves. The flow rate was controlled by a sonic nozzle and a venturi tube. Gas-nitrogen acted as a purge gas for rapid flameout and cooled down. The dynamic pressure in the combustion chamber was measured using a CYB20S/DT pressure transducer, which had an accuracy of \pm $0.25 \% \mathrm{FS}$ and a rise time of $1 \mu \mathrm{s}$.

Figure 4 presents the delay characteristics of a practical liquid rocket engine delivery system. The propellant underwent a certain delay from the opening of the valve signal to the injection into the thrust chamber, which was primarily attributed to the valve response time and fluid filling in the pipeline and head cavity. Figure 5 illustrates the results of the cold flow test of oxygen and kerosene. Both GOX and kerosene valves received an opening signal at $0 \mathrm{~s} .0 \mathrm{~s}-$ $0.16 \mathrm{~s}$ comprised the delay time of the oxygen valve and the filling time of the pipeline before the nozzle, as suggested from Figure 5(a). At $0.18 \mathrm{~s}$, the pressure in the combustion 


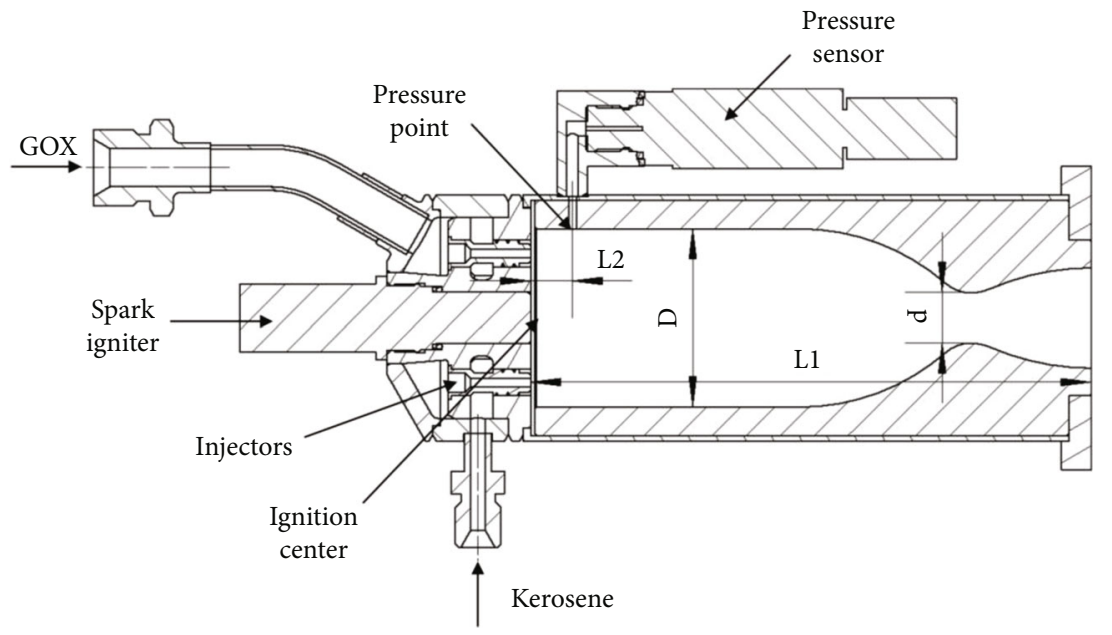

FIgURE 1: Schematic of combustor from different views.

TABLE 1: Size parameters of thrust chamber.

\begin{tabular}{lcccccccc}
\hline Geometric features & $L_{1}$ & $L_{2}$ & $D$ & $d$ & $l_{1}$ & $l_{2}$ & $l$ & $N$ \\
\hline Dimension value & $148.3 \mathrm{~mm}$ & $11 \mathrm{~mm}$ & $47 \mathrm{~mm}$ & $13.2 \mathrm{~mm}$ & $5 \mathrm{~mm}$ & $2.4 \mathrm{~mm}$ & $22 \mathrm{~mm}$ & 3 \\
\hline
\end{tabular}

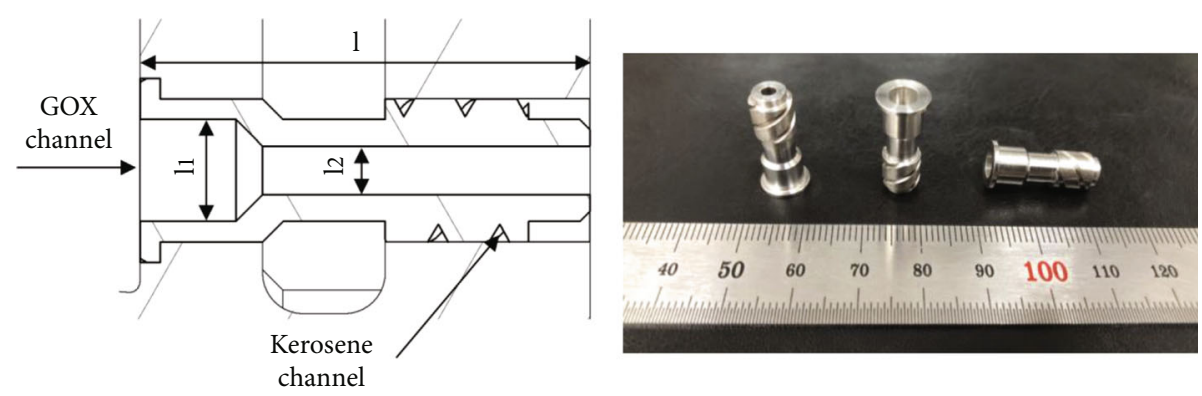

Figure 2: Schematic and photograph of combustor injectors.

chamber increased, thereby revealing that oxygen began to enter the combustion chamber at this moment. After $0.7 \mathrm{~s}$, the combustion chamber pressure accesses into a steady state. For kerosene, since the kerosene thrust chamber cavity was significantly bigger than the head cavity, the pressure before the injection of kerosene could be determined, whereas the thrust chamber pressure could not be established, as illustrated from Figure 5(b). Besides, kerosene should go through a certain length of pipe and head cavity from the preinjection pressure measurement point to the thrust chamber. For this reason, the accurate time for kerosene to enter the thrust chamber could not be obtained. The variable here was the filling time of oxygen, and the opening time of the kerosene valve remained unchanged. Thus, the time for kerosene to enter the thrust chamber did not impact the result analysis.

\section{Simulation Model and Conditions}

3.1. Numerical Methods. Kerosene exhibits numerous advantages (e.g., normal atmospheric temperature and easy storage). However, kerosene is a complex mixture of components. For
CFD simulation, some kerosene substitute models have been studied successively to simplify the model and the calculation $[20,21]$. In this paper, a ten-step quasiglobal chemical kinetics model for kerosene fuel combustion (Table 2) was adopted to conduct chemical reaction rate calculations. The mentioned mechanism is capable of simulating the kerosene combustion accurately, and it exhibits higher computational efficiency than more complex mechanisms [22].

The Reynolds-averaged Navier-Stokes (RANS) numerical method was adopted to express the complete gas dynamics model. The Navier-Stokes equation was averaged over time and then introduced into the model for solution. The mentioned method involves relatively simplified calculation, and it is applicable to engineering numerical calculations.

The realizable $k-\varepsilon$ model acted as a fluid turbulence model. The realizable $k-\varepsilon$ model introduced constraints on Reynolds stress, and the treatment of Reynolds stress remained consistent with real turbulence. Moreover, the model could more accurately simulate the diffusion velocity of planar and circular jets. In the calculation of rotating flow, boundary layer calculation with directional pressure 


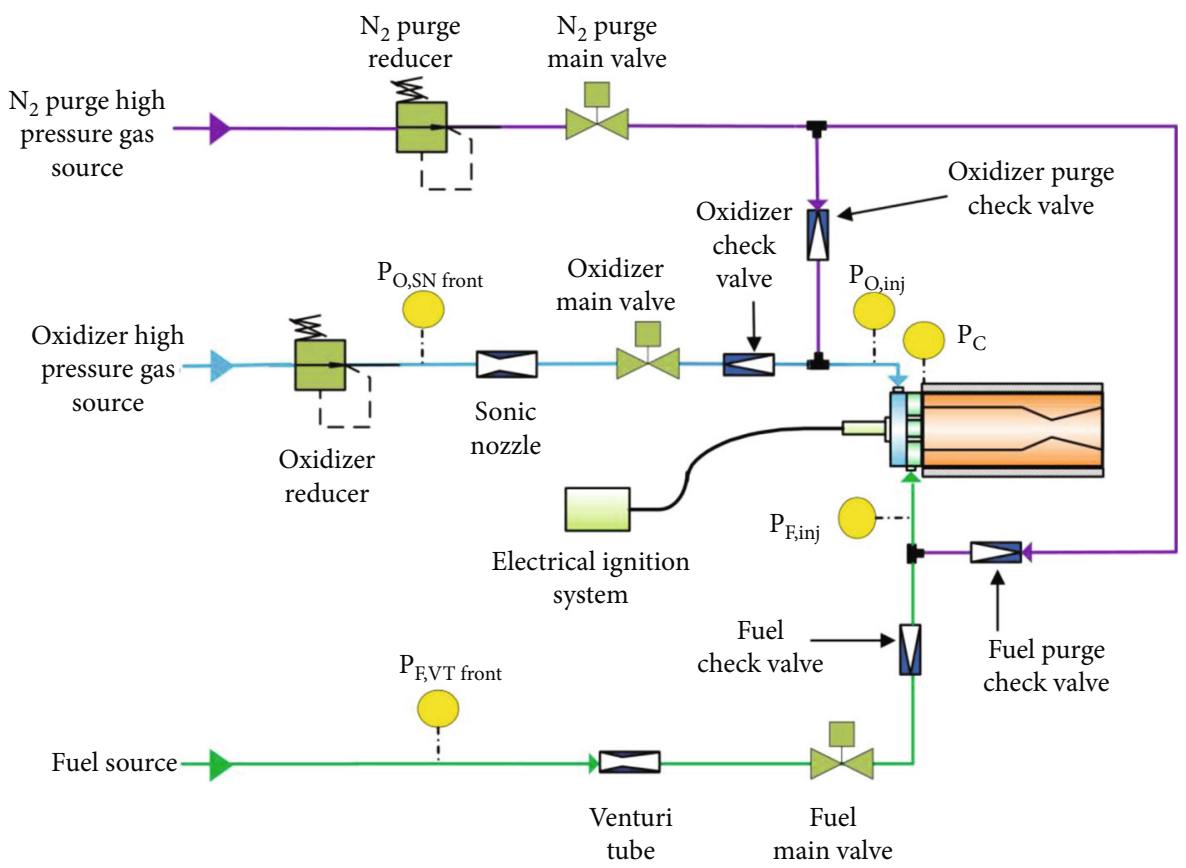

FIGURE 3: Piping and instrument diagram of the combustion experiment facility.

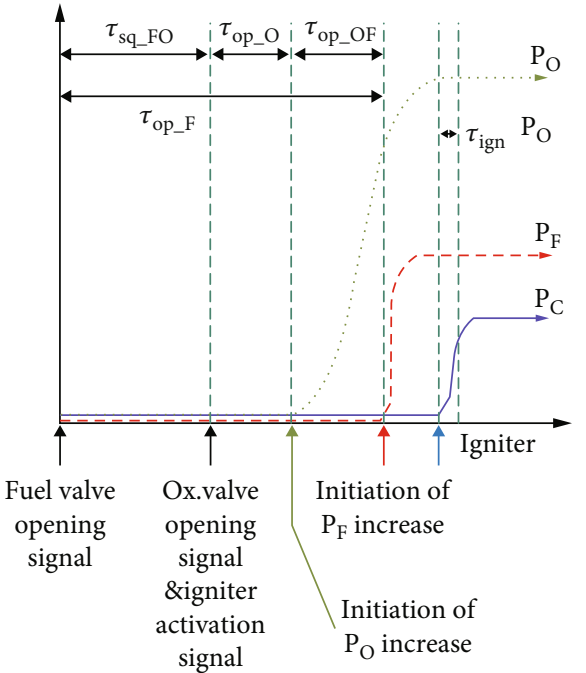

FIGURE 4: Time delays in the practical liquid rocket engine system.

gradient, and separation flow calculation, the calculation results more significantly complied with the practical situation [23]. The RNG $k-\varepsilon$ turbulence model contained two transport equations of turbulence kinetic energy and dissipation, as expressed below:

$$
\begin{gathered}
\frac{\partial}{\partial t}(\rho k)+\frac{\partial}{\partial x_{i}}\left(\rho k u_{i}\right)=\frac{\partial}{\partial x_{j}}\left[\left(\mu+\frac{\mu_{t}}{\sigma_{k}}\right) \frac{\partial k}{\partial x_{j}}\right]+G_{k}-\rho \varepsilon, \\
\frac{\partial}{\partial t(\rho \varepsilon)}+\frac{\partial}{\partial x_{j}}\left[\left(\mu+\frac{\mu_{t}}{\sigma_{k}}\right) \frac{\partial k}{\partial x_{j}}\right]+\rho C_{1} E \varepsilon-C_{2} \rho \frac{\varepsilon^{2}}{k+\sqrt{v \varepsilon}},
\end{gathered}
$$

where $k$ denotes turbulent kinetic energy, $\varepsilon$ is the dissipation rate, $\sigma_{k}$ and $\sigma_{\epsilon}$ represent the Prandtl numbers corresponding to $k$ and $\varepsilon$, respectively; $x_{i}$ and $x_{j}$ denote the position coordinate components, the molecular viscosity coefficient $\mu=\rho C_{\mu} k^{2} / \sigma_{\varepsilon}$, the production term of turbulent kinetic energy $k$ attributed to the average velocity gradient $G_{k}=\mu_{t} S^{2}$, the turbulent viscosity $\mu_{t}=\rho_{1} C_{\mu} k^{2} / \varepsilon, C_{\mu}$ is recognized as a function related to the average changed rate and turbulent flow field, the modulus of the mean rate of strain tensor $S=\sqrt{2 S_{i j} S_{i j}}$ and $S_{i j}=(1 / 2)\left(\left(\partial u_{i} / \partial x_{j}\right)+\left(\partial u_{j} / \partial x_{i}\right)\right)$. Furthermore, the coefficients in the above realizable $k-\varepsilon$ equations included $C_{1}=\max [0.43,(\eta / \eta+5)], \eta=S k / \varepsilon, \sigma_{k}$ $=1.0, \sigma_{\epsilon}=1.2$, and $C_{2}=1.9$.

The chemical reaction rate was determined by adopting the Arrhenius formula, and the eddy current dissipation concept (EDC) model was selected to simulate the interaction between the chemical reaction and the turbulence. This model is capable of simulating the detailed chemical reaction mechanism. The chemical reaction was assumed to occur in a small vortex. With the reactant components reaching a sufficiently uniform molecular level and the temperature reaching the reaction temperature, the reaction could proceed. In other words, the consumption of propellant was largely determined by the mixing level of fuel and oxygen. The reaction time was regulated by the survival time of the small vortex and the time required for the chemical reaction. The scale of the small vortex was calculated as

$$
\gamma=C_{\xi}\left(\frac{\nu \varepsilon}{k^{2}}\right)^{1 / 4}
$$




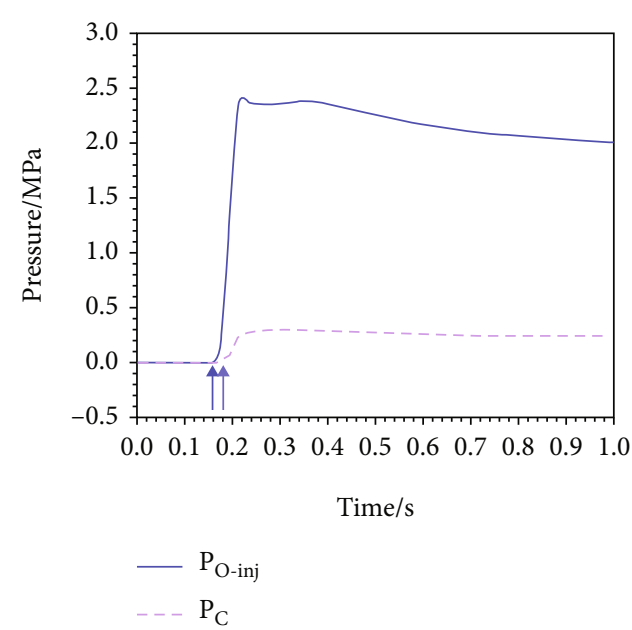

(a)

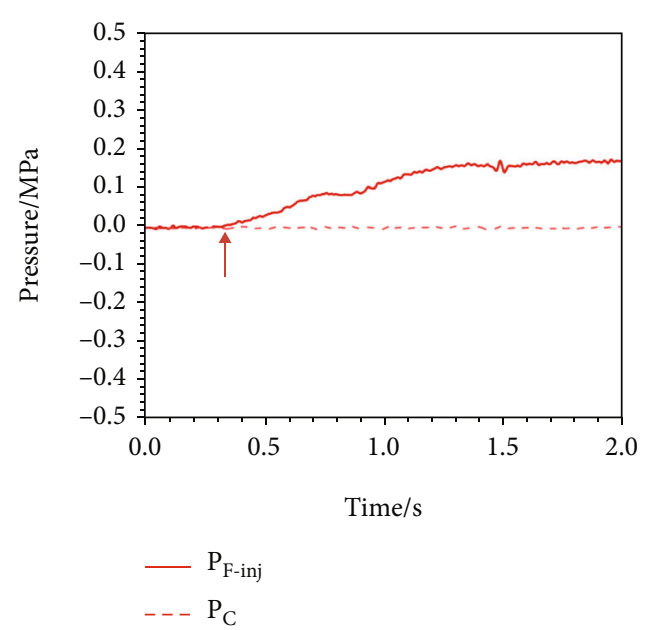

(b)

Figure 5: Pressure of cold flow test data: (a) GOX and (b) kerosene.

TABle 2: Chemical reaction mechanism.

\begin{tabular}{lccc}
\hline Reaction considered & $A$ & $b$ & $E$ \\
\hline 1. $\mathrm{C}_{10} \mathrm{H}_{20}+5 \mathrm{O}_{2}<=>10 \mathrm{CO}+10 \mathrm{H}_{2}$ & $2.00 E+16$ & 0.0 & 52000.0 \\
2. $\mathrm{CO}+\mathrm{O}+\mathrm{M}<=>\mathrm{CO}_{2}+\mathrm{M}$ & $5.30 E+13$ & 0.0 & -4540.0 \\
3. $\mathrm{CO}+\mathrm{OH}<=>\mathrm{CO}_{2}+\mathrm{H}$ & $4.40 E+06$ & 1.5 & -740.0 \\
4. $\mathrm{H}_{2}+\mathrm{O}_{2}<=>\mathrm{OH}+\mathrm{OH}$ & $1.70 E+13$ & 0.0 & 48000.0 \\
5. $\mathrm{H}+\mathrm{O}_{2}<=>\mathrm{OH}+\mathrm{O}$ & $2.60 E+14$ & 0.0 & 16800.0 \\
6. $\mathrm{OH}+\mathrm{H}_{2}<=>\mathrm{H}_{2} \mathrm{O}+\mathrm{H}$ & $2.20 E+13$ & 0.0 & 5150.0 \\
7. $\mathrm{O}+\mathrm{H}_{2}<=>\mathrm{OH}+\mathrm{H}$ & $1.80 E+10$ & 1.0 & 8900.0 \\
8. $\mathrm{OH}+\mathrm{OH}<=>\mathrm{H}_{2} \mathrm{O}+\mathrm{O}$ & $6.30 E+13$ & 0.0 & 1090.0 \\
9. $\mathrm{H}+\mathrm{H}+\mathrm{M}<=>\mathrm{H}_{2}+\mathrm{M}$ & $6.40 E+17$ & -1.0 & 0.0 \\
10. $\mathrm{H}+\mathrm{OH}+\mathrm{M}<=>\mathrm{H}_{2} \mathrm{O}+\mathrm{M}$ & $2.20 E+22$ & -2.0 & 0.0 \\
\hline
\end{tabular}

where $\gamma$ denotes the mass fraction of reactants in the fine structure, $C_{\xi}$ represents the volume ratio constant, $v$ is the kinematic viscosity of the dissipation zone, and $\varepsilon$ and $\kappa$ represent the turbulent energy dissipation rate and turbulent kinetic energy, respectively. In this time scale, matter was subject to a time scale $\tau^{*}$, as defined below:

$$
\tau^{*}=C_{\tau}\left(\frac{\nu}{\varepsilon}\right)^{1 / 2}
$$

where $C_{\tau}$ denotes the time scale constant. The reaction rate is defined as

$$
\frac{\omega_{i}}{\rho}=\frac{\gamma^{2} \chi}{\tau^{*}}\left(Y_{i}^{0}-Y_{i}^{*}\right)
$$

where $\rho$ represents the density of the reactant, $\chi$ denotes the reaction fraction of the fine structure, $\chi=1$; $Y_{i}^{*}$ represents the mass fraction of component $i$ in the fine structure, and $Y_{i}^{0}$ expresses the original mass fraction of component $i$ outside the reactor. The chemical reaction of

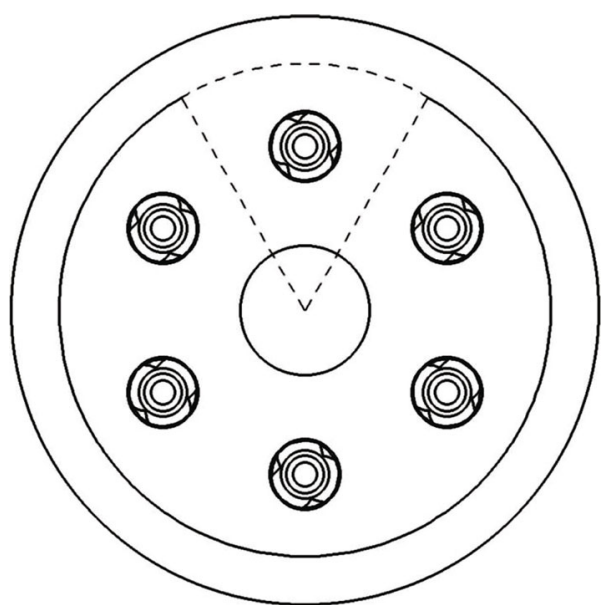

Figure 6: The nozzle distribution of injector.

the small vortex took place under equal conditions. The initial conditions referred to the current composition and temperature in the unit. The numerical integration method was adopted to calculate the reactant state $Y_{i}^{*}$.

The coupled algorithm based on the pressure solver was taken to solve the continuous equation of the flow field, the momentum equation, the energy equation, the turbulence equation, and the chemical reaction equation.

3.2. Mesh Methods and Boundary Conditions. Oxygen was injected in a straight line at the center of the injector, and kerosene rotates through three spiral gaps in the circumferential direction of the injector and entered the thrust chamber. The injector consisted of 6 evenly distributed nozzles, which was presented in Figure 6. Since the model was characterized by circumferential symmetry, one-sixth of the combustion chamber was used for the simulation to simplify the calculation. 3D structured meshes with nodes all exceeding 350000 were draw out. The mesh and boundary conditions are illustrated in Figure 7. To enhance the calculation accuracy near the wall, enhanced wall treatment, which 


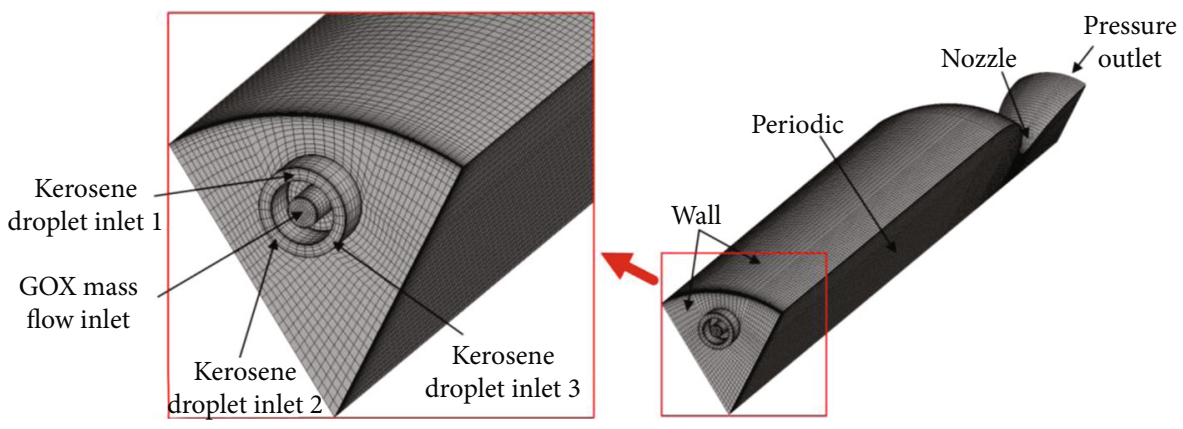

FIgURe 7: Mesh overall view (a) and partial enlarged view of injector (b).

was a near-wall modeling method combining a two-layer model with so-called enhanced wall functions was adopted. The first node of the computational meshes was adjusted to $0.01 \mathrm{~mm}$, so the $y$-plus value was equal to 1 approximately. Moreover, the results of mesh dependency conducted indicated the mesh satisfied the numerical simulation under the nodes quantity exceeding 300000 .

Oxygen was injected into the thrust chamber along the centerline with the mass flow inlet. The discrete phase method was adopted to simulate kerosene droplets. Moreover, the starting point of the droplets calculation domain was taken at the outlet of the kerosene swirl nozzle. The inlet velocity was calculated by the flow formula. In addition, the nozzle thread lift angle reached $30^{\circ}$, and the velocity vector of the kerosene inlet could be calculated as the entry condition of droplets. Table 3 illustrates the specific inlet boundary conditions.

The outlet condition of the thrust chamber adopted the pressure outlet. The internal symmetry plane adopted periodic boundary conditions. Since this paper did not consider the boundary heat transfer effect, the remaining walls used adiabatic wall boundary conditions.

3.3. Ignition Model. The spark ignition model in ANSYS FLUENT was exploited for the numerical simulation. The submesh spark model was transferred to the CFD mesh via a representative volume of CFD cells. Such a volume was spherical and exhibited a fixed diameter computed as the local turbulent length scale at the spark location. Nevertheless, to ensure that this representative volume was not extremely large (relative to the size of the combustor) or too small (relative to the cell size), the radius of the representative sphere, was calculated as

$$
r_{t}=\max \left(r_{o}+3 \Delta, \min \left(\frac{1}{2} l_{t}, r_{o}+10 \Delta\right)\right)
$$

where $r_{o}$ denotes the user-specified initial spark radius, $\Delta$ represents the cell length scale, and $l_{t}$ expresses the turbulent length scale.

ANSYS FLUENT defines $c=\left(r / r_{t}\right)^{3}$ as the reaction progress in the representative volume, where $r$ represents the spark radius. The temperature and species composition
TABle 3: Numerical inlet conditions.

\begin{tabular}{lccccc}
\hline & $\begin{array}{c}\dot{m}(\mathrm{~g} / \\
\mathrm{s})\end{array}$ & $\begin{array}{c}V_{x}(\mathrm{~m} / \\
\mathrm{s})\end{array}$ & $\begin{array}{c}V_{y}(\mathrm{~m} / \\
\mathrm{s})\end{array}$ & $\begin{array}{c}V_{z}(\mathrm{~m} / \\
\mathrm{s})\end{array}$ & $\begin{array}{c}P_{0} \\
(\mathrm{MPa})\end{array}$ \\
\hline $\begin{array}{l}\text { GOX } \\
\text { Kerosene inlet } \\
1\end{array}$ & 22.92 & - & - & - & 2 \\
$\begin{array}{l}\text { Kerosene inlet } \\
2\end{array}$ & 3.47 & 13.06 & 0 & 22.54 & - \\
$\begin{array}{l}\text { Kerosene inlet } \\
3\end{array}$ & 3.47 & 13.06 & 19.52 & -11.27 & - \\
\hline
\end{tabular}

\begin{tabular}{|c|c|c|c|}
\hline Channel & Signal timeing chart & On $(\mathrm{ms})$ & Off (ms) \\
\hline GOX & 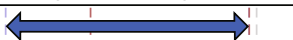 & 150 & 5050 \\
\hline Kerosene & $\Rightarrow$ & 0 & 5050 \\
\hline Igniter & $\Rightarrow$ & 150 & 2850 \\
\hline $\mathrm{N}_{2}$ purge & $\sqrt{2}$ & 5200 & 10200 \\
\hline
\end{tabular}

FIGURE 8: Ignition time sequence of three test conditions.

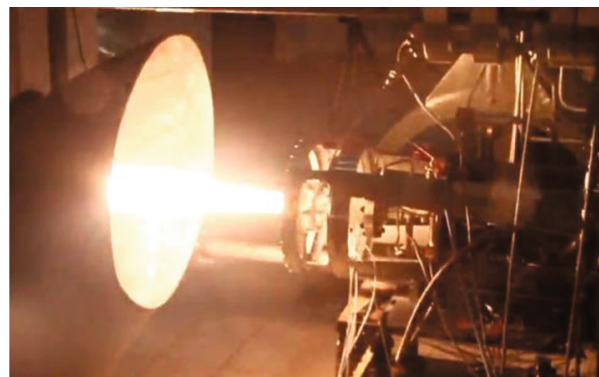

FIGURE 9: Pictures of hot-firing test for typical operating condition.

(denoted by $\varphi$ ) in the representative spherical volume at the respective time-step were calculated as

$$
\varphi=c \varphi^{b}+(1-c) \varphi^{u}
$$

where $\varphi^{b}$ denotes the equilibrium burnt composition and $\varphi^{u}$ represents the unburned composition. The mentioned compositions were fixed in time and uniform in space.

The ignition energy of the electric spark igniter applied in this research test was $1 \mathrm{~J}$, and the ignition frequency was $50 \mathrm{~Hz}$. For the simulation, the ignition energy remained set 


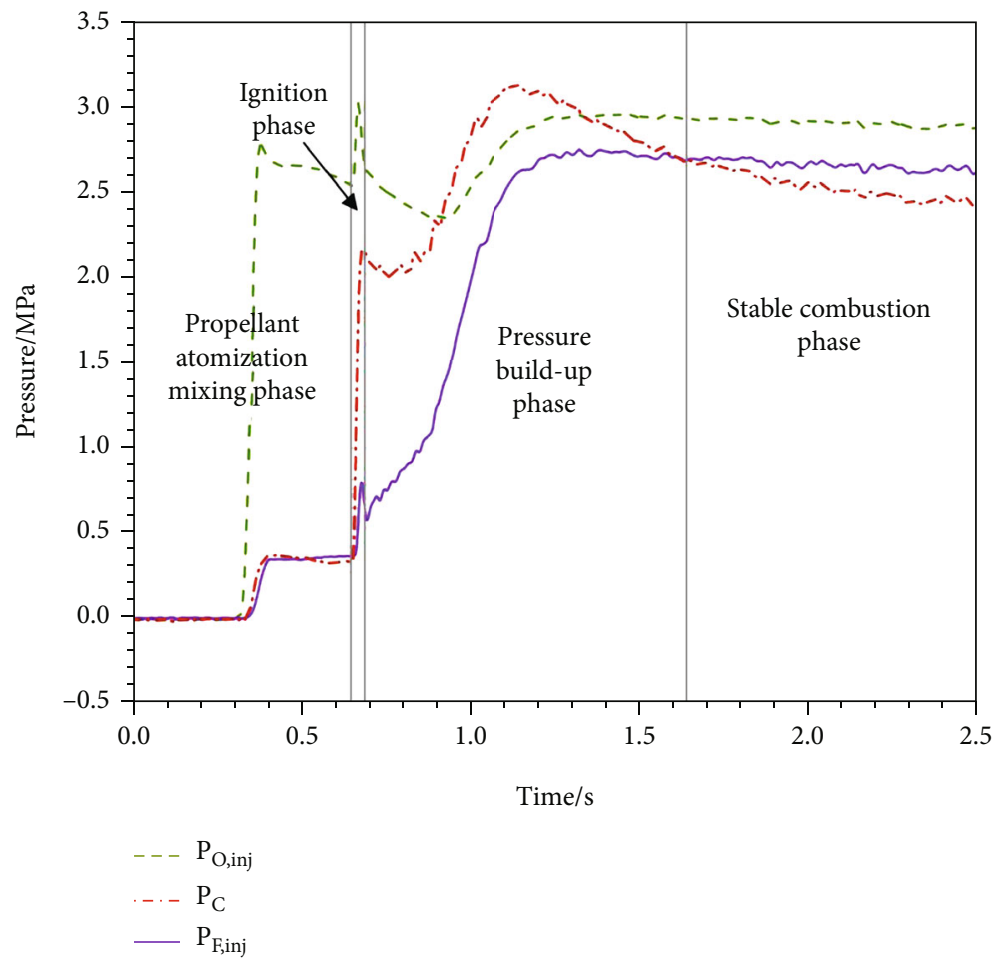

Figure 10: Pressure curve for measuring points in the system.

to $1 \mathrm{~J}$. The ignition center was the position of the electrode of the test igniter, and the initial radius of the spark reached $1 \mathrm{~mm}$. The ignition energy was turned on while supplying kerosene droplets to the combustion chamber and it was turned off after $5 \mathrm{~ms}$. The mentioned duration also complied with the working characteristics of high-energy igniter [24]. It was assumed that ignition could be achieved in this period, so the issue of the frequency of the converter was ignored.

\section{Results and Discussion}

4.1. Test Results of Ignition Pressure Building. In this section, the general law of combustion chamber pressure was explored by performing the ignition test. Subsequently, the effect of oxygen prefill time on the ignition was discussed by altering the ignition sequence.

Figure 8 illustrates the control sequence of the engine ignition test. The oxygen valve and the igniter were opened simultaneously, $150 \mathrm{~ms}$ later than the fuel valve. After the system operated for nearly $5 \mathrm{sec}$, the oxidizer valve and the fuel valve were closed. Moreover, the nitrogen valves were opened to turn off the system. The thrust chamber was fixed on the thrust bench by using the fixing device. Figure 9 presents the scene image of the hot-firing test.

According to Figure 10, the pressure building of the combustion chamber could fall to four parts, i.e., the propellant atomization mixing phase, the ignition phase, the pressure build-up phase, and the stable combustion phase.

The pressure before the oxygen injection $\left(P_{O \text {,inj }}\right)$ began to rise at $0.32 \mathrm{~s}$. After a delay of nearly $30 \mathrm{~ms}$, the pressure in the combustion chamber $\left(P_{C}\right)$ began to increase, demonstrating that oxygen began to fill the combustion chamber, and the pressure
TABLE 4: Valve opening and ignition signal setting for three working conditions.

\begin{tabular}{lccc}
\hline $\begin{array}{l}\text { Working } \\
\text { condition }\end{array}$ & $\begin{array}{c}\text { Fuel valve } \\
\text { opening signal } \\
(\mathrm{ms})\end{array}$ & $\begin{array}{c}\text { Oxidizer valve } \\
\text { opening signal (ms) }\end{array}$ & $\begin{array}{c}\text { Ignition } \\
\text { signal (ms) }\end{array}$ \\
\hline Case 1 & 0 & 150 & 150 \\
Case 2 & 0 & 50 & 50 \\
Case 3 & 0 & 0 & 0 \\
\hline
\end{tabular}

before the fuel injection $\left(P_{F, \text { inj }}\right)$ increased as impacted by oxygen filling. This state continued till $0.65 \mathrm{~s}$, and the three pressures appeared to surge, thereby demonstrating that ignition occurred at this time. Accordingly, nearly $0.3 \mathrm{~s}$ was taken from the initiation of oxygen injection into the thrust chamber to the occurrence of ignition. In a very short period, the combustion chamber pressure increased from $0.33 \mathrm{MPa}$ to $2.15 \mathrm{MPa}$. According to the pressure curve, $P_{F \text {,inj }}$ was always lower than $P_{C}$ in this stage. The reason for this phenomenon was that a stainless steel pipe was installed between the measuring point and the sensor, and the compressibility of the air in the elbow caused the measurement delay. The purpose was to avoid sensors directly contacting with kerosene. This does not mean that the fuel injection was blocked because the upstream pressure was significantly larger than the thrust chamber pressure.

Due to the prefilling of oxygen in the thrust chamber, excess oxygen continued to burn with the added kerosene, which further increased the thrust chamber pressure. After $1.62 \mathrm{~s}$, the combustion chamber pressure tended to be stable and then changed into the stable combustion stage. Furthermore, the ignition phase was mainly discussed here. 


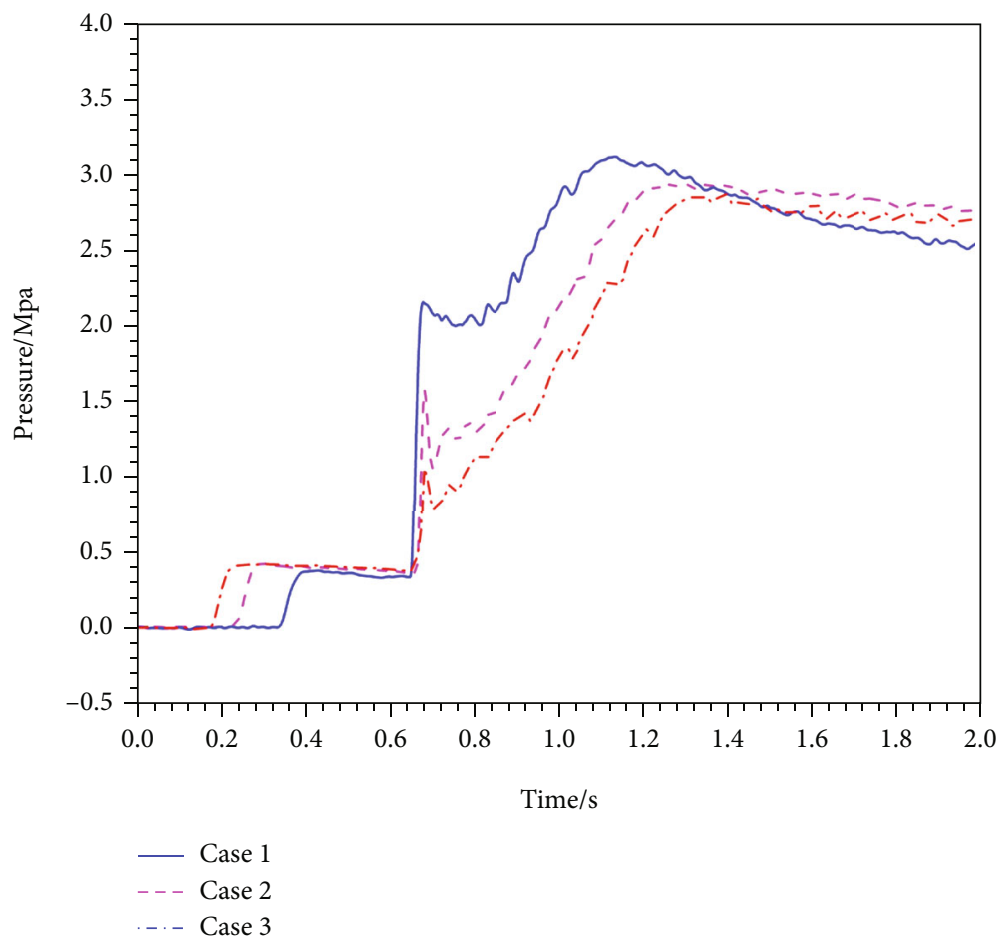

FIGURE 11: Combustion chamber pressure of three ignition test conditions.

By regulating the opening time of the oxygen valve, the effect of the oxygen prefilling time on the ignition was explored. Table 4 lists the time sequence of the valve opening signal and the ignition. The oxygen valve signal was delayed by $150 \mathrm{~ms}$, $50 \mathrm{~ms}$, and $0 \mathrm{~ms}$ from the fuel valve signal. The ignition signal was opened synchronously with the oxygen valve opening signal. Under the three working conditions, before the kerosene entered the thrust chamber, the ignition energy reached the rated state. Subsequently, the consistency was ensured.

Figure 11 presents the test results. The three working condition curves all contained four phases of the pressure building, indicating that ignition moments were nearly $650 \mathrm{~ms}$. Therefore, the oxygen prefilling time insignificantly impacted the ignition timing. Pressure peaks occurred in all three cases, i.e., 2.25 $\mathrm{MPa}, 1.66 \mathrm{MPa}$, and $1.05 \mathrm{MPa}$, respectively. The higher oxygen content in the combustion chamber before ignition generated a smaller ignition pressure peak. In the presence of preinjected oxygen in the combustion chamber, the kerosene droplets entered the combustion chamber and instantly burned violently with oxygen, thereby resulting in pressure peaks. Under the extremely high oxygen content, the propellant $O / F$ flow ratio in the combustion chamber was extremely small, probably inhibiting the occurrence of deflagration. Thus, to avoid deflagration in the ignition phase, the oxygen preinjection time should be regulated to avoid the optimal $O / F$ flow ratio interval.

\subsection{Analysis of Ignition Stage}

4.2.1. Analysis of the Pressurizing Process. To explore the ignition in depth, the ANSYS FLUENT platform was employed to conduct a transient simulation of the ignition. The model was built to simulate the identical ignition tested

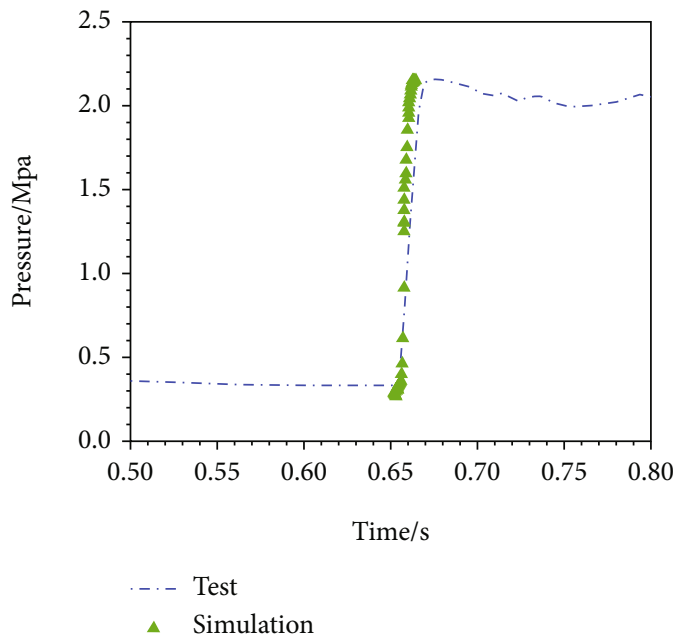

FIGURE 12: Comparison of the pressurizing process during ignition between the experimental and numerical results.

in case 1 where the oxidation valve and the fuel valve opening time interval reached $150 \mathrm{~ms}$. According to Section 2.2, kerosene injection time could not be determined here, whereas the oxygen injection time before ignition could be indicated from a pressure curve. For case 1, the actual oxygen filling time was $300 \mathrm{~ms}$ according to Figure 10. As impacted by the prefilling of oxygen, kerosene would be ignited in a very short period after entering the thrust chamber. Accordingly, the cold flow simulation of oxygen for $300 \mathrm{~ms}$ was performed first, and then, kerosene droplets were injected to complete the ignition. To verify the accuracy of the model, the identical pressure measurement point 


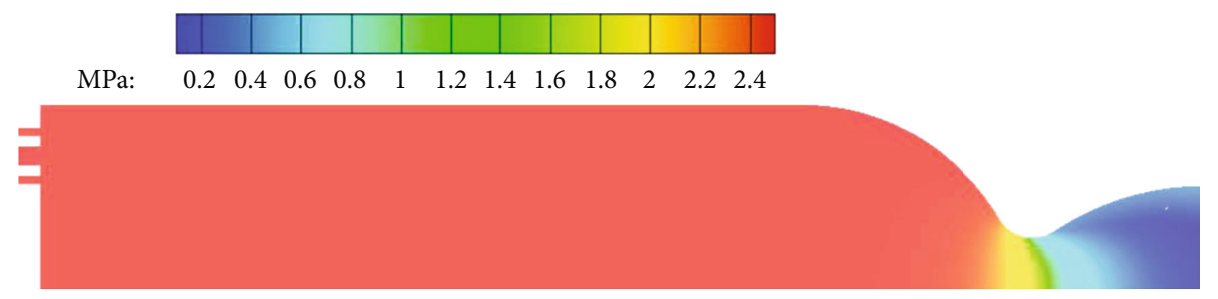

FIGURE 13: Steady state pressure distribution of case 1.

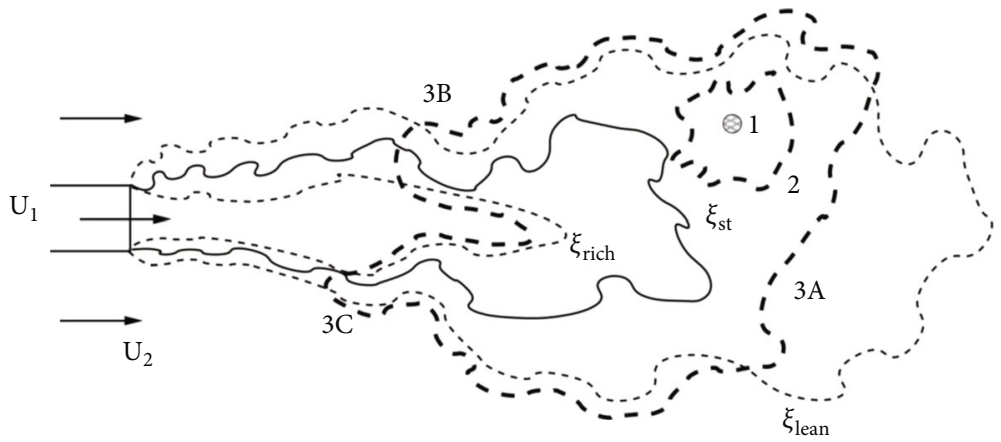

FIGURE 14: Schematic of the kernel expansion process following localized ignition. U1: the fuel-carrying fluid; U2: the oxygen-carrying fluid; 1: kernel immediately following ignition; 2 : small turbulent stratified-charge premixed flame; $3 \mathrm{~A}$ : turbulent stratified-charge premixed flame, 3B: edge flame, low mixture fraction gradient; 3C: edge flame, high mixture fraction gradient $[26,27]$.

was adopted to compare the pressure build-up process during the ignition. The relevant results are presented in Figure 12. The numerical results well complied with the test results (pressurizing period and pressure peak value), thereby proving the accuracy of the simulation and the reasonableness of the assumptions here. To express the pressurizing of the chamber specifically, the starting point of ignition delay time was defined, i.e., the combustion chamber pressure reached 15\% (higher than the oxygen filling pressure) of the stable pressure, and the endpoint was defined as the pressure peak. Under the $O / F$ flow ratio of 2.2 , the stable pressure of combustion chamber reached 2.5 $\mathrm{MPa}$, so the starting and ending pressures of ignition were $0.37 \mathrm{MPa}$ and $2.15 \mathrm{MPa}$, respectively. For this reason, the pressurizing periods in the simulation and the test were $14 \mathrm{~ms}$ and $20 \mathrm{~ms}$, respectively. In order to further verify the accuracy of the simulation model, casel was simulated in steady state. Figure 13 shows the steady-state pressure distribution under this condition. The simulation result of combustion chamber pressure was $2.5 \mathrm{MPa}$ (gauge pressure), while the steady-state pressure of the test result was $2.43 \mathrm{MPa}$ as shown in Figure 10. The error is only $2.9 \%$. Therefore, the CFD model could reflect the real combustion state of the thrust chamber.

\subsubsection{The Formation of Flame Kernel and Flame} Development. The overall ignition of the jet flame fell to two phases, i.e., the formation of the initial fire core, as well as the flame propagation along the jet to initiate the whole flame. Sufficiently, high ignition energy and uniform propellant mixing refer to the necessary conditions for successful ignition [25]. Specific to turbulent nonpremixed combustion, Figure 14 presents several characteristics of the ignition, schematically showing the flame propagation in the turbulent fuel jet after successful ignition [26, 27]. $\xi_{s t}$ denotes isolines of the stoichiometric mixture fraction, and $\xi_{\text {lean }}$ and $\xi_{\text {rich }}$ represent the isolines corresponding to the lean and rich static flammability limits. The area between $\xi_{\text {lean }}$ and $\xi_{\text {rich }}$ was the ignition area, since the propellant mixing in this area was subject to the flammable conditions. As the ignition energy tended to be accumulated in this area, a small kernel would be generated at a certain position, displaying an approximately spherical reaction zone (1). This flame exhibited premixed characteristics, whereas due to the nonpremixed flow, the combustible equivalent ratio varied in a limited range. Such a scenario can be termed as the propagation of a premixed flame in a stratified mixture, demonstrating that the fluctuation of the turbulent mixture fraction was in the flammability limit. Next, the flame would be propagated by complying with the stoichiometric mixture fraction, i.e., it might actually move along the $\xi_{s t}$ isoline. Lastly, the flame propagation turned out to be a stable turbulent jet flame, attached to the nozzle or lift, which was determined by the jet and coflow velocity [28].

Figure 15 illustrates the numerical simulation of flame propagation in the combustion chamber. At $0 \mathrm{~s}$, kerosene droplets started to be injected into the combustion chamber, and oxygen formed a stable flow field (Figure 16). The central recirculation zone (CRZ) exhibited a large scale before ignition, with a span of nearly $80 \mathrm{~mm}$. Kerosene and oxygen were mixed and atomized at the injector for nearly $4 \mathrm{~ms}$, and ignition occurred around the injector rather than close to the 


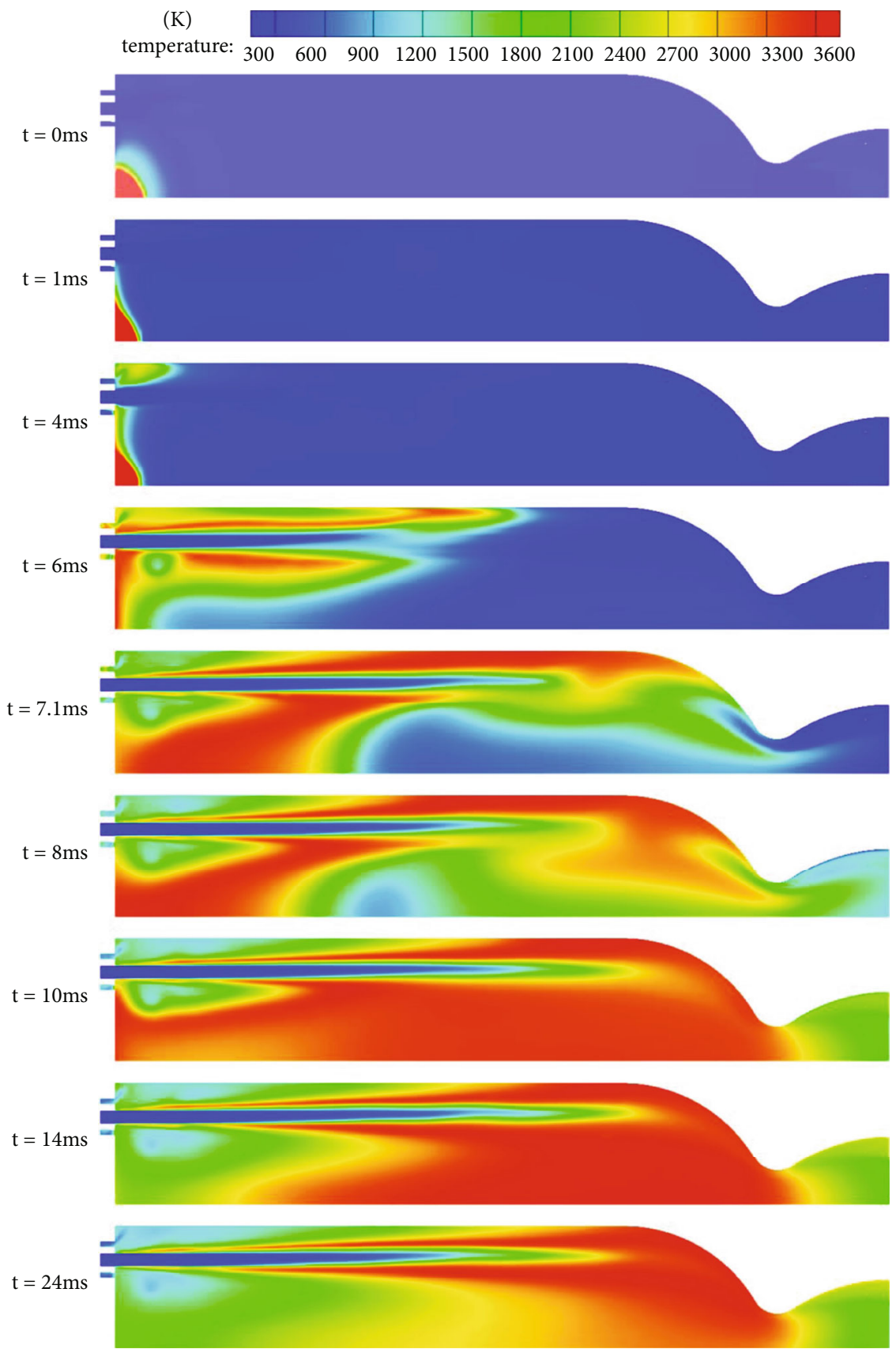

FIGURE 15: The evolution of temperature field during ignition at $z=0 \mathrm{~mm}$ plane.

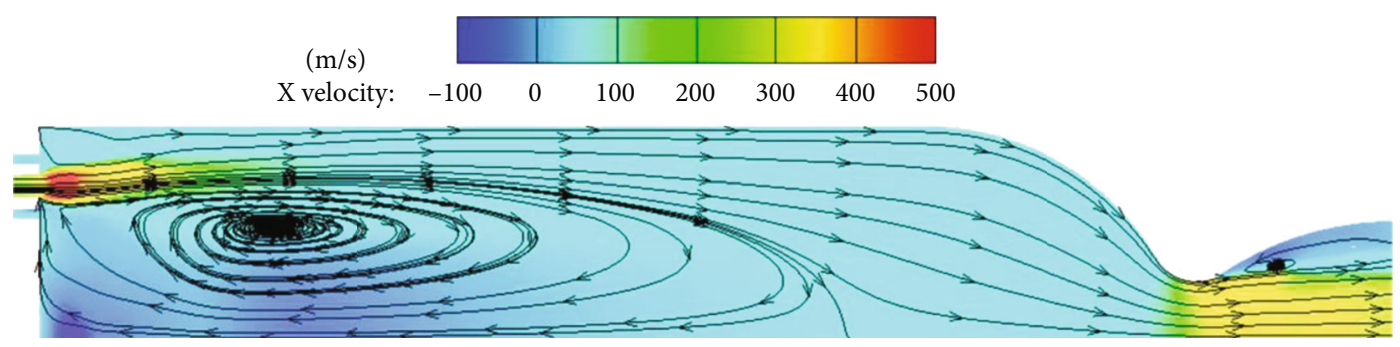

FIGURE 16: Streamlines of oxygen injection $0.3 \mathrm{~s}$. Background are colored by mean axial velocity. 


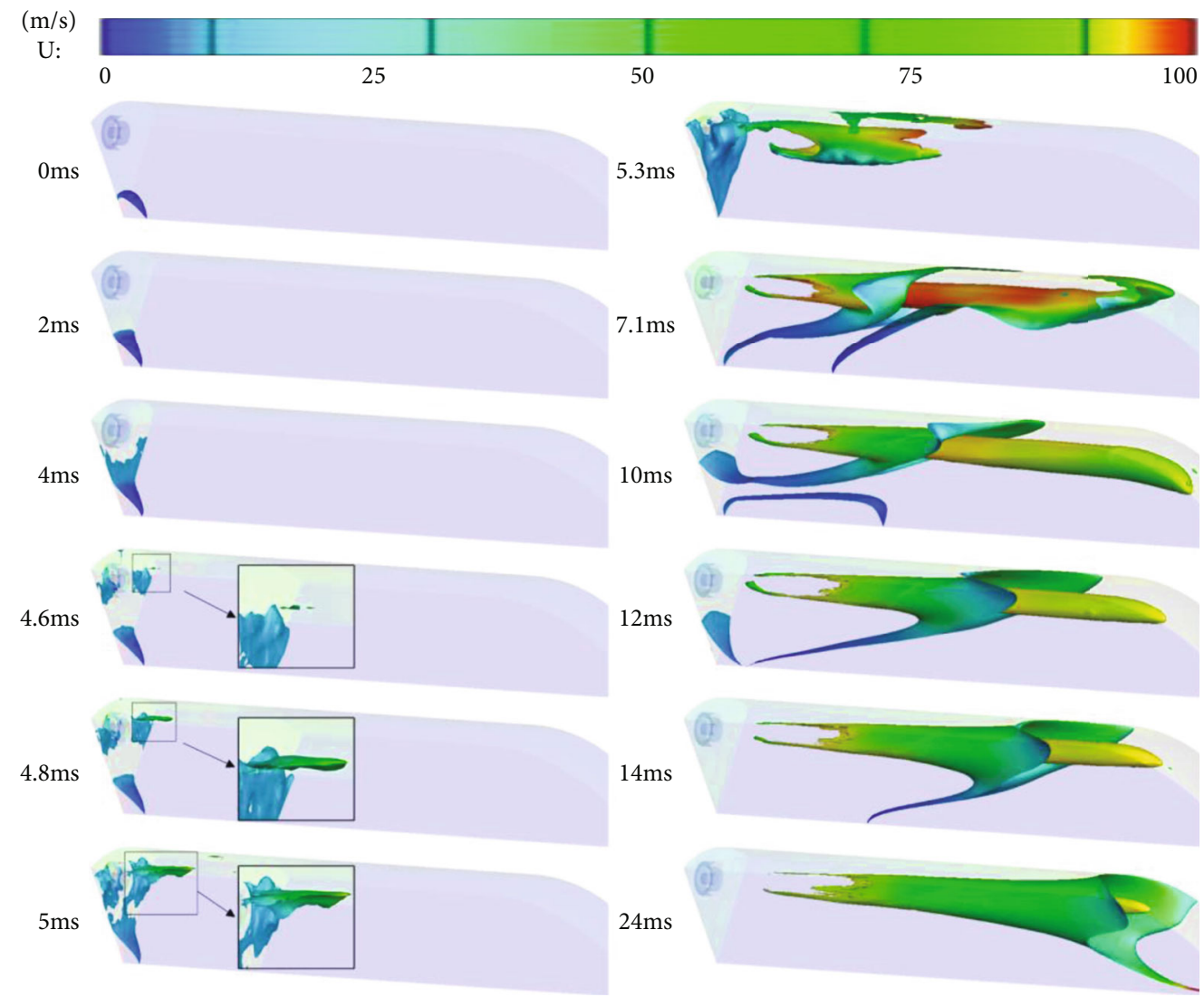

Figure 17: Isosurface of $T=3400 \mathrm{~K}$ of statistically stationary stabilized flame for fine mesh. The surface is colored by instantaneous axial velocity.

igniter. This result is explained as after the spark was propagated rapidly, the heat and free radicals generated at the spark convection to the flammable area, and ignition occurred $[29,30]$. In addition, the laminar flame simulation indicated that transportation of the heat and free radicals might facilitate forced ignition [31]. The mentioned ignition method via energy transport was not dependent of the mixing characteristics of the propellant in the ignition spark region, the ignition was more reliable, and the ignition delay was shorter. The ignition timings of the three different working conditions were basically identical, thereby verifying the previous argument. During the flame propagation, the propagation speed at the wall of the combustion chamber exceeded that of the central area. After nearly $7.1 \mathrm{~ms}$, the flame was propagated to the throat area.

The thermodynamic calculation was conducted with chemical equilibrium with applications (CEA). RP-1 was used as the fuel to replace kerosene, and the $O / F$, nozzle expansion ratio, and combustion chamber pressure were set as $2.2,4$, and $2.5 \mathrm{MPa}$, respectively, according to the working conditions. The theoretical value of the combustion flame temperature of the propellant was nearly $3400 \mathrm{~K}$. Accordingly, the isosurface was extracted to explore the flame surface propagation using this temperature (Figure 17). As clearly observed from the figure, before $4 \mathrm{~ms}$, the high-temperature zone was deformed as impacted by the central recirculation zone and gradually moved radi- ally into the injector direction. At nearly $4.6 \mathrm{~ms}$, a kernel exhibiting the diameter of the injector $(2 \mathrm{~mm})$ was generated. The kernel was $6 \mathrm{~mm}$ away from the injector, located at the oxygen and kerosene mixing interface and approaching the upper wall. Afterwards, the kernel was developed rapidly along the axial direction, reaching a scale of nearly $15 \mathrm{~mm}$ in $5 \mathrm{~ms}$. With the injection of the propellant, the flame was propagated upstream and downstream in the range of stoichiometric mixture fraction. In $6 \mathrm{~ms}-$ $20 \mathrm{~ms}$, the central recirculation zone was involved in the flame propagation. The common method of stabilizing the flame in high-speed gases is using a recirculation zone, which can be generated by using a bluff body or a strong swirl. The flame was propagated rapidly in the downstream direction after flowing, and the recirculation zone should be fully ignited to successfully create and stabilize the overall flame [9]. As impacted by the flow velocity too high to spread directly, the flame should reach the bottom of the recirculation zone via the convection of the recirculation flow.

\section{Conclusion}

In this paper, ignition tests and simulations were performed for the rocket engine combustion chamber applied in RBCC engine. The ignition and combustion of the GOX/kerosene swirl injection were investigated, which achieved an easier 
prediction of the mixed flow behavior of the propellant. The results and discussion help optimize existing calculation methods to be more feasible in predicting experimental results. The main conclusions are shown below:

(1) The pressurizing of ignition largely fell to four phases, i.e., the propellant atomization mixing phase, ignition phase, pressure build-up phase, and stable combustion phase. It took nearly $1.4 \mathrm{~s}$ from the beginning of ignition to the stability of combustion chamber pressure

(2) The ignition delay under typical working conditions was nearly $20 \mathrm{~ms}$. The oxygen prefilling time slightly impacted the ignition timing, primarily affecting the size of the ignition pressure peak. In a confined range, the ignition pressure peak declined with the extension of oxygen prefilling time

(3) As revealed from the numerical calculations, under prefilled oxygen, the ignition energy moved radially along the injection panel as impacted by CRZ. As a result, the kernel $6 \mathrm{~mm}$ away from the injector was formed. In $2 \mathrm{~ms}$, after the kernel was formed, the flame was rapidly propagated along the axial direction in the range of the stoichiometric mixture fraction. Subsequently, the flame was propagated in the CRZ by convection and then reached a steady state after nearly $20 \mathrm{~ms}$

\section{Nomenclature}

\section{Variables}

$L_{1}$ : Total length of combustion chamber

$L_{2}$ : Distance between pressure measuring point and injector panel

$D$ : Diameter of cylinder section of combustor

$d$ : Combustor throat diameter

$l_{1}$ : Diameter of oxidant inlet section of injector

$l_{2}$ : Diameter of oxidant outlet section of injector

$l$ : Total length of injector

$N$ : Number of spiral grooves

$\tau: \quad$ Time interval

$\tau_{\text {ign }}:$ Ignition delay time

$\dot{m}$ : Mass flow rate

$V: \quad$ Velocity

$P$ : $\quad$ Pressure

T: $\quad$ Temperature

$O / F$ : Oxidizer/fuel mixture ratio

$U$ : Axial velocity.

\section{Subscripts}

O: Oxidizer

$F$ : Fuel

SN: Sonic nozzle

inj: Injection

VT: Venturi tube

C: Combustion chamber sq: The sequence of valve signal

op: Valve opening.

\section{Data Availability}

The data of experimental results and numerical simulation results in this study are available from the corresponding author upon request.

\section{Conflicts of Interest}

The authors declare that they have no known competing financial interests or personal relationships that could have appeared to influence the work reported in this article.

\section{References}

[1] L. Shi, Y. Yang, G. Zhao et al., "Research and development on inlets for rocket based combined cycle engines," Progress in Aerospace Sciences, vol. 117, p. 100639, 2020.

[2] D. K. Bonnar, M. J. Bulman, and A. Siebenhaar, The Role of the Strutjet Engine in New Global and Space Markets, NASA Center for Aerospace Information (CASI), United States, 1998.

[3] A. Siebenhaar and M. J. Bulman, "The Strutjet engine - The overlooked option for space launch," in 31st Joint Propulsion Conference and Exhibit, San Diego, CA, USA, July 1995.

[4] X. Rui, H. Xin, L. Feixing et al., "A survey on the conceptual design of hypersonic aircraft powered by RBCC engine," Proceedings of the Institution of Mechanical Engineers, Part C: Journal of Mechanical Engineering Science, vol. 2141153511, p. 095440622098201, 2021.

[5] M. Nakane, D. Kobayashi, H. Yoshida, and Y. Ishikawa, "Feasibility study on single stage to orbit space plane with RBCC engine," in 16th AIAA/DLR/DGLR International Space Planes and Hypersonic Systems and Technologies Conference, Bremen, Germany, 2011.

[6] B. An, M. Sun, Z. Wang, and J. Chen, "Cavity flameholding subjected to an expansion fan in a rocket-based combined cycle combustor," Aerospace Science and Technology, vol. 106, p. 106180, 2020.

[7] J. Li, G. Zhu, S. Zhang, O. Yan, W. Li, and F. Qin, "Two-stage fuel injection performance of RBCC under scramjet mode," Aerospace Science and Technology, vol. 105, p. 106062, 2020.

[8] L. Shi, G. Zhao, Y. Yang, F. Qin, X. Wei, and G. He, "Experimental study on ejector-to-ramjet mode transition in a divergent kerosene-fueled RBCC combustor with low total temperature inflow," Aerospace Science and Technology, vol. 99, p. 105734, 2020.

[9] O. Gurliat, V. Schmidt, O. J. Haidn, and M. Oschwald, "Ignition of cryogenic H2/LOX sprays," Aerospace Science and Technology, vol. 7, no. 7, pp. 517-531, 2003.

[10] M. Takegoshi, S. Tomioka, S. Ueda, T. Saito, and O. Hayasaka, "Firing-tests of a rocket combustor for combined cycle engine at various conditions," in 41st AIAA/ASME/SAE/ASEE Joint Propulsion Conference \& Exhibit, Tucson, Arizona, July 2005.

[11] M. Takegoshi, S. Tomioka, F. Ono, T. Saito, and M. Soejima, "Injectors and combustion performance of rocket thruster for rocket-ramjet combined-cycle engine model," in AIAA/3AF International Space Planes \& Hypersonic Systems \& Technologies Conference, Tours, France, 2013. 
[12] M. Takegoshi, S. Tomioka, S. Ueda, T. Saito, and O. Hayasaka, "Performances of a rocket chamber for the combined-cycle engine at various conditions," in 14th AIAA/AHI Space Planes and Hypersonic Systems and Technologies Conference, Canberra, Australia, November 2006.

[13] D. Kim, M. Son, and J. Koo, "Ignition transition of coaxial kerosene/gaseous oxygen jet," Combustion Science and Technology, vol. 188, no. 11-12, pp. 1799-1814, 2016.

[14] D. Kim, B. Shin, S. Choi, and J. Koo, "Effects of pre-filled gas and spraying condition on ignition of oxygen/kerosene spray combustion," Combustion and Flame, vol. 167, pp. 1-13, 2016.

[15] H. Sheng, X. Huang, Y. Ji, Z. Zhao, Z. Chen, and H. Liu, "Synergistic promotion of multi-component RP-3 kerosene lowtemperature ignition with addition of radical activator," International Journal of Hydrogen Energy, vol. 46, no. 53, pp. 27207-27220, 2021.

[16] L. Xuan, L. Tian, H. Jinli, Z. Shaohua, and X. Xu, “The preliminary study of oxygen-centered kerosene-swirl coaxial injector," in AIAA/ASME/SAE/ASEE Joint Propulsion Conference, Cleveland, OH, USA, 2013.

[17] W. Chu, X. Li, Y. Tong, and Y. Ren, "Numerical investigation of the effects of gas-liquid ratio on the spray characteristics of liquid-centered swirl coaxial injectors," Acta Astronautica, vol. 175, pp. 204-215, 2020.

[18] S. Soller, R. Wagner, H. P. Kau, P. Martin, and C. Maeding, "Combustion stability characteristics of coax-swirl-injectors for oxygen/kerosene," in 43rd AIAA/ASME/SAE/ASEE Joint Propulsion Conference \& Exhibit, Cincinnati, OH, July 2007.

[19] B. Lin, Y. Wu, M. Xu, and Z. Chen, "Experimental investigation on spark ignition and flame propagation of swirling kerosene spray flames," Fuel, vol. 303, p. 121254, 2021.

[20] J. R. Ryley, M. Mcgilvray, and D. Gillespie, "Local heat transfer coefficient measurements on an engine-representative internal cooling passage," Journal of Thermophysics and Heat Transfer, vol. 33, no. 1, pp. 189-198, 2019.

[21] W. Ten-See, "Thermophysics characterization of kerosene combustion," Journal of Thermophysics \& Heat Transfer, vol. 15, no. 2, pp. 140-140, 2001.

[22] J. Y. Choi, "A quasi global mechanism of kerosene combustion for propulsion applications," in AIAA/ASME/SAE/ASEE Joint Propulsion Conference \& Exhibit, San Diego, CA, USA, 2013.

[23] T.-H. Shih, W. W. Liou, A. Shabbir, Z. Yang, and J. Zhu, “A new $k-\epsilon$ eddy viscosity model for high Reynolds number turbulent flows," Computers \& Fluids, vol. 24, no. 3, pp. 227238, 1995.

[24] J. Dale, "Application of high energy ignition systems to engines," Progress in Energy and Combustion Science, vol. 23, no. 5-6, pp. 379-398, 1997.

[25] K. Hamai, H. Kawajiri, T. Ishizuka, and M. Nakai, "Combustion fluctuation mechanism involving cycle-to-cycle spark ignition variation due to gas flow motion in S.I. engines," Symposium (International) on Combustion, vol. 21, no. 1, pp. 505$512,1988$.

[26] G. Sorrentino, Characterization of advected-surfaces. The sinews of a "MultiSECtioning" approach for non-premixed combustion, 2013.

[27] E. Mastorakos, "Ignition of turbulent non-premixed flames," Progress in Energy and Combustion Science, vol. 35, no. 1, pp. 57-97, 2009.

[28] K. M. Lyons, "Toward an understanding of the stabilization mechanisms of lifted turbulent jet flames: experiments," Prog- ress in Energy and Combustion Science, vol. 33, no. 2, pp. 211231, 2006.

[29] S. F. Ahmed, R. Balachandran, and E. Mastorakos, "Measurements of ignition probability in turbulent non-premixed counterflow flames," Proceedings of the Combustion Institute, vol. 31, no. 1, pp. 1507-1513, 2007.

[30] S. F. Ahmed, "The probabilistic nature of ignition of turbulent highly-strained lean premixed methane-air flames for lowemission engines," Fuel, vol. 134, pp. 97-106, 2014.

[31] E. S. Richardson and E. Mastorakos, "Numerical investigation of forced ignition in laminar counterflow non-premixed methane-air flames," Combustion Science and Technology, vol. 179, no. 1-2, pp. 21-37, 2007. 